\title{
UMA ANÁLISE DA ELABORAÇÃO DO CÓDIGO COMERCIAL BRASILEIRO À LUZ DA DOUTRINA E DEBATES LEGISLATIVOS HISTÓRICOS
}

\section{AN ANALYSIS OF THE DEVELOPMENT OF BRAZILIAN COMMERCIAL CODE UNDER THE HISTORIC DOCTRINE AND LEGISLATIVE DEBATES}

\author{
${ }^{1}$ Alexandre Ferreira de Assumpção Alves \\ ${ }^{2}$ Raphael Vieira da Fonseca Rocha
}

\section{RESUMO}

O artigo analisa os debates na Câmara dos Deputados nos anos que precederam a promulgação do Código Comercial, especialmente a votação do projeto em bloco. Como questão prévia, analisam-se brevemente os aspectos gerais do ordenamento jurídico brasileiro anterior ao diploma em questão, com o intuito de contextualizar a realidade vigente no período estudado. Por fim, está inserido no recorte expor como restaram reguladas a justiça comercial e a falência no Código Comercial, com o objetivo de exemplificar algumas das soluções que prevaleceram. A pesquisa é do tipo bibliográficadocumental e o método adotado é o dedutivo.

Palavras-chave: História do direito, Código comercial, Jurisdição comercial, Falência

\begin{abstract}
The paper analyzes the debates in the Chamber of Deputies in the years preceding the enacting of the Commercial Code, especially the adoption en bloc of the project. As preliminary matter, it analyses briefly the general aspects of Brazilian legal system previous to the statute in question, in order to contextualize the current reality of the studied period. Finally, it's within its scope setting out how commercial jurisdiction and bankruptcy were regulated by the Commercial Code, in order to illustrate some of the solutions that prevailed. It's a bibliographical and documentary research and the method adopted is deductive.
\end{abstract}

Keywords: History of law, Commercial code, Commercial jurisdiction, Bankruptcy

\footnotetext{
${ }^{1}$ Doutor em Direito pela Universidade do Estado do Rio de Janeiro - UERJ, Rio de Janeiro - RJ (Brasil). Professor da Universidade do Estado do Rio de Janeiro - UERJ, Rio de Janeiro - RJ (Brasil).

E-mail: asaa@uol.com.br

${ }^{2}$ Mestrando em Direito na Universidade do Estado do Rio de Janeiro - UERJ, Rio de Janeiro - RJ (Brasil).

E-mail: raphael_rocha_16@hotmail.com
} 


\section{INTRODUÇÃO}

O presente artigo tem por objetivo analisar os debates travados na Câmara dos Deputados nos anos antecederam a aprovação do Código Comercial (Lei n ${ }^{\circ}$ 556, de 25 de junho de 1850), centrando-se na discussão em torno da votação do projeto em bloco. Como questão prévia, o escopo é realizar breve análise dos aspectos gerais do ordenamento jurídico pátrio anterior ao diploma em questão, com o intuito de contextualizar o leitor acerca da realidade vigente no período estudado. Por fim, almeja-se expor como restaram reguladas a justiça comercial e a falência no Código, dois assuntos muito debatidos pelos deputados, com o objetivo de exemplificar algumas das soluções que prevaleceram em resposta às demandas dos comerciantes.

O corrente estudo encontra-se situado na seara da história do direito, uma vez que se utiliza de métodos historiográficos na tentativa de entender criticamente o passado, sem que o direito deixe de ocupar o centro da preocupação teórica. Seu corte será na história do direito comercial nacional, perpassando também por temas clássicos empresariais como, v.g., falência, reabilitação do falido, atos de comércio, jurisdição comercial, porém sempre visando os aspectos histórico-jurídicos do instituto.

O tema escolhido visa contribuir para a formação de uma cultura jurídica mais consolidada na seara histórica e na própria sociedade, especialmente no meio acadêmico. Busca-se descontruir a visão de uma História do Direito feita de certezas superficiais, factual, sem uma análise crítica, estudada com uma metodologia rasa e voltada tão somente para legitimar as instituições do presente. Só assim a ciência jurídica pode discutir adequadamente direito e desigualdades e caminhar corretamente para prever diagnósticos precisos para um Brasil justo. Saliente-se que o Código Comercial foi um diploma elitista, criado para a preservação dos interesses das camadas mais ricas da sociedade e dos comerciantes abastados.

Ao longo do artigo serão utilizadas, primordialmente, fontes histórico-jurídicas, em especial os Anais da Câmara dos Deputados do Império, doutrina da época e análise de textos originais das normas citadas, optando sempre por transcrevê-los conforme a própria redação de seu tempo ${ }^{3}$. O objetivo é imergir o leitor nessa visão histórica dos tempos do Brasil Império, fazendo-o compreender, dentro do possível, os institutos estudados da 
forma como eram concebidos à época. Também serão utilizadas fontes atuais sistematizadoras, diante das reais possibilidades de tempo e dedicação ao tema para sua confecção, porém em menor intensidade. ${ }^{4}$

Foram analisados os textos originais dos Anais da Câmara dos Deputados do Império em uma nova perspectiva, voltada para uma análise jurídica da votação em bloco do Código Comercial e de dois importantes assuntos - a justiça comercial especializada e a falência, debatidos à luz da doutrina dos anos subsequentes à elaboração do Código.

Como método científico, adota-se o dedutivo, pelo qual o raciocínio lógico faz uso da dedução para obter uma conclusão a respeito de determinada premissa. A pesquisa é do tipo bibliográfico-documental, partindo-se da análise dos debates travados no legislativo pátrio e outros documentos histórico-jurídicos para expor uma visão sobre o tema, produzindo conclusões pessoais com supedâneo nas premissas adotadas no material investigatório coligido. Afinal "fatos históricos" estão sujeitos à interpretação dos elementos mentais do pesquisador ${ }^{5}$.

\footnotetext{
${ }^{3}$ Feita essa ressalva, optou-se por não colocar sic em todos os trechos citados ao longo desse trabalho. Isso porque a redação da época era bastante diferente da atual

40 Interesse pelo tema surgiu da leitura do artigo de autoria de Roberto N. P. F. Saba (As praças comerciais do Império e a aprovação do Código Comercial Brasileiro na Câmara dos Deputados. Revista Angelus Novus, nº 1, agosto de 2010. Disponível em: <http://www.revistas

5Segundo matriz filosófica idealista, fatos e eventos não possuem materialidade exterior ao pensamento. O que existe são tão somente ideias acerca desses fatos, possuindo o historiador do direito apenas um conjunto de concepções mentais que o permitem entender e/ou criar a História. Isto é, o objeto da pesquisa fica condicionado. Ao sujeito pesquisado. Nas palavras de Ricardo Marcelo Fonseca "haveria apenas elaborações subjetivas sobre o passado do direito, tomadas
} 
possíveis, através da consciência" (FONSECA, Ricardo Marcelo. Introdução a História do Direito. $3^{\mathrm{a}}$ reimpressão. Curitiba: Juruá. 2012.p.25).

\title{
2. TRAÇOS GERAIS DO ORDENAMENTO JURÍDICO ANTERIOR À ELABORAÇÃO DO CÓDIGO COMERCIAL
}

Em 1823, a Assembleia Geral Constituinte legislativa do Império do Brasil decretou:

\begin{abstract}
As Ordenações, Leis, Regimentos, Alvarás, Decretos, e resoluções promulgadas pelos Reis de Portugal, e pelas quaes o Brazil se governava até o dia 25 de Abril de 1821, em que Sua Magestade Fidelissima, actual Rei de Portugal, e Algarves, se ausentou desta Côrte; e todas as que foram promulgadas daquela data em diante pelo Senhor D. Pedro de Alcantara, como Regente do Brazil, em quanto Reino, e como Imperador Constitucional dele, desde que se erigiu em Imperio, ficam em inteiro vigor na parte, em que não tiverem sido revogadas, par por ellas se regularem os negócios do interior deste Imperio, emquanto se não organisar um novo Codigo, ou não forem especialmente alteradas.6 (g.n)
\end{abstract}

Posteriormente, o Imperador Pedro I, por Carta de Lei de 20 de outubro de 1823, mandou executar o referido Decreto. No ano seguinte, a Constituição de 1824, atenta à necessária provisoriedade deste dispositivo, estipulou em seu art. 179, inciso XVIII, que se deveria organizar " quanto antes um Código Civil, e Criminal, fundado nas solidas bases da Justiça, e Equidade" 7. Considerando que o Código Comercial brasileiro foi promulgado tão somente em 1850, durante esses anos continuou sendo aplicada a emaranhada legislação colonial, demonstrando um elemento de continuidade com a tradição jurídica portuguesa 8 , que de certo não atendia às demandas da sociedade brasileira da época.

Além disso, não era novidade a aplicação de leis estrangeiras não portuguesas em solo brasileiro, situação corriqueira no país antes e depois da Independência. Isso porque o ordenamento português, que anteriormente constituía um único tronco em relação ao direito brasileiro, permitia o uso, v.g., do direito romano, do direito canônico, da Glosa de Acúrsio e das Opiniões de Bártolo para suprir as lacunas de sua legislação. A situação era tão normal que o Marquês de Pombal editou a Lei de 18 de agosto de 1769 (Lei da Boa Razão) para suprimir os abusos cometidos na aplicação desse direito:

$6 \mathrm{Cf}$. http://www.2.camara.leg.br/atividadelegislativa/publicacoes/doimperio>

7 Inobstante essa prescrição constitucional, o Código Criminal só foi promulgado em 1830; o Comercial, como se verá, em 1850, e o civil, tão somente em 1916, já em plena República. 
8 FONSECA, Ricardo Marcelo. A cultura jurídica brasileira e a questão da codificação civil no século XIX, Revista da faculdade de direito da UFPR. V. 44, n. 0 (2016),p. $65 . \quad$ Disponível em:http://ojs.c3sl.ufpl.br/ujs2/index.php/direito/article/view/9415/6507. Acesso em 28/12/2015.

de fato, a lei de 18 de agosto de 1769, alcunhada de "Lei da boa razão" amplamente ancorada num ambiente cultural iluminista e jusnaturalista, buscava basicamente impor novos critérios de interpretação e integração das lacunas na lei. O seu primeiro cuidado é precisamente o de reprimir o abuso, até então vulgarizado, de recorrer aos textos de direito romano ou a textos doutrinais em desprezo a disposições expressas do direito nacional português. Desse modo, tornava-se proibido o uso nas decisões judiciais de textos romanos ou invocar a autoridade de algum escritor quando houve disposição em contrário nas Ordenações, nos usos do reino ou nas leis pátrias. Somente nos casos de lacunas é que se poderia recorrer aos textos romanos. É de se frisar, porém, que assim o direito romano, como 'Direito subsidiário', não poderia ser utilizado em si mesmo, mas sim, por meio da 'recta ratio' dos jusnaturalista, a 'boa razão'.9

Antes do Código Comercial, não havia uma justiça especializada para causas comerciais. Tanto questões civis quanto comerciais eram julgadas por um único juízo. Contudo, a doutrina já vinha tecendo elogios a nações que haviam especializado a matéria, conforme se percebe em excerto da lavra de José da Silva Lisboa, o Visconde de Cairu:

Restabelecendo-se as Letras na Europa, e reconhecendo as grandes Nações Maritimas a importancia do Commercio para a grandeza dos Estados, e felicidade dos Povos, e do Genero Humano, os mais illuminados Governos erigirão Tribunaes de Commercio terrestre e marítimo, não só para promoverem o bem da Industria e Trafico do respectivo Paiz, em todas as relações com a economia interior da Nação, sua Agricultura, Manufactura, e Navegação, mas tambem para julgarem das causas mercantis entre Commerciantes, e por contracto, derivados de operações de seu Commercio. ${ }^{10}$

Saliente-se que cidadãos ingleses e franceses possuíam privilégios em razão de sua nacionalidade, estando submetidos à figura dos Juízes Conservadores, ficando a justiça comum adstrita aos comerciantes brasileiros:

9 FONSECA, Ricardo Marcelo. Op. Cit., p. 6364. 
10 CAYRU, José da Silva Lisboa, Visconde de. Princípios de Direitos Mercantil e leis da Marinha, dividos em sete tratados elementares, contendo a respectiva, legislação patria, indicando as fontes originais dos regulamentos marítimos das principais praças da Europa. Tomo II, $6^{\circ}$ ed. Rio de Janeiro: Typographia Academica, 1874, p. 849.

\begin{abstract}
Se estabelecêrão Juizes Conservadores particulares em privilegio das Nações Ingleza e Franceza[...]. No nosso Reino a Nação Ingleza tem o privilegio de ter hum Juiz Conservador, de que não se pode interpor apellação, mas só aggravo ordinario para a Caza de Supplicação, em virtude do Alvará de 31 de Março de 1790. [...] Quanto ás outras causas mercantis dos Commerciantes, são competentes Juizes em $1^{\text {a }}$ Instancia os Ouvidores Geraes do Civil, ou o Juiz dos Moedeiros, quando o Author, ou o Réo tem este privilegio. ${ }^{11}$
\end{abstract}

Havia, ainda, a figura da Junta do Comércio, criada pelo Decreto de 30 de setembro de 1755, cujos estatutos constitutivos foram confirmados pelo Alvará de 16 de dezembro do mesmo ano. A Junta, com o decorrer do tempo, foi elevada a Tribunal Supremo pela Lei de 5 de junho de 1788, passando a possuir como principal objetivo a promoção da "recta economia do comercio, e Industria Nacional"12 Importa ressaltar que lhe foi atribuída jurisdição exclusiva para conhecer de matérias relativas à falência do comerciante, em conjunto com a Secretaria de Estado.

A Junta era um órgão especializado, de modo que os agravos e apelações interpostos em face dos juízes de $1^{a}$ Instância, julgadores de causas mercantis, não se dirigiam a ela, mas ao Supremo Tribunal de Justiça do respectivo território de jurisdição, exceto em causas referentes a seguros, cujas apelações das sentenças arbitrais proferidas, após homologadas pelo Presidente da Casa de Suplicação, eram endereçadas à Real Junta do Comércio ${ }^{13}$.

Portanto, antes da elaboração do Código, os assuntos comerciais, na sua maioria eram regulados por normas que não atendiam às demandas dos comerciantes ou não possuíam qualquer regulação pelas leis do Império, o que levava ao juiz, diante de uma lide, a aplicar a confusa teia legislativa ainda de origem colonial ou recorrer a leis das chamadas "nações mais civilizadas" sem que houvesse um ajustiça especializada. 
11 Idem,p.849 850

12 Ide, p. 850

13 BRASIL, CazadeSupplicaão. Assento de7defevereiro de 1793, CAYRU, José da Silva Lisboa, visconde de Op. Cit, p. 850

\title{
3. OS DEBATES TRAVAdOS EM PROL DA APROVAÇÃO EM BLOCO DO CÓDIGO COMERCIAL
}

Em uma comissão nomeada pelo governo regencial, José da Silva Lisboa estava presente e foi figura central na elaboração do projeto do Código Comercial, entregue em $1834^{14}$. Nessa época não havia uma oficialização dos vínculos entre negociantes e autoridades públicas do Estado brasileiro. Contudo, considerando-se que boa parte da receita do país vinha dos impostos sobre importações, pode-se afirmar que a voz dos comerciantes era bastante relevante para aqueles preocupados com assuntos estatais 15 .

Em $1^{\circ}$ de julho de 1843 , nove anos após a elaboração do projeto, nota-se, ainda que tímida, a aparição de uma indicação do deputado João Manuel Pereira da Silva, in verbis:

\begin{abstract}
Attendendo a que a commissão especial, nomeada pela camara dos Srs. senadores, já declarou haver finalisado os trabalhos da organisação de um código commercial, medida tão vital e tão imperiosamente reclamadas pelas circunstâncias actuais e urgentes necessidades do paiz, tendo já pedido autorisação á sua respectiva camara para publicar o projecto elaborado por ella; e attendendo a que a commissão especial nomeada pela camara dos Srs. deputados, substituindo áquella que na sessão anterior fôra nomeada, devêra ligar-se com a commissão do senado para melhor facilidade dos trabalhos, índico-que a commissão especial do codigo do commercio, nomeada por esta camara, exponha á casa o resultado de suas fadigas, e com urgencia promova o andamento e satisfação de uma necessidade tão clamorosa como a de uma lei mercantil, que fixa a legislação, e defina os crimes commerciais que possão ser punidos pelos competentes tribunaes afim de terminar esse terrivel cahos de intelligencias, interpretações e opiniões sobre taes matérias, e a continuação de repetidas banca-rotas que entre nós se sucedem com escandalo quasi todos os dias. Paço da camara dos Srs. deputados, em sessão de 17 de Junho de 1843. - J. M. Pereira da Silva16
\end{abstract}

14 Além de José da Silva Lisboa, contribuíram também na elaboração do projeto do Código comercial brasileiro.

Limpo de Abreu, Ignacio Ratton, Guilhrme Midose, Laurencie Westin e José Clemente Pereira. Quase todos os idealizadores do diploma comercial eram indivíduos vinculados a atividades comerciais.

15 SABA, Roberto N. P. F. Op.Cit, p. 78. 
16 BRASIL, Anais da Câmara dos deputados. Sessão de 01 de julho de 1843, p. 13. Disponivel em: < http://imagem.camara.gov.br/diarios.asp>. Acesso em 29.12.2015.

Analisando-se a indicação do deputado, pode-se extrair algumas reivindicações dos comerciantes da época. Por exemplo, vê-se que um dos grandes problemas que os comerciantes enfrentavam era a fragilidade da legislação colonial para lidar com as falências de má-fé, gerando um enorme risco à atividade mercantil daqueles que honestamente dirigiam seus negócios. Para Roberto Saba, a pressão feita pelos comerciantes foi de vital importância para a aprovação do Código Comercial. Segundo o autor, ao longo da década de 1840, os comerciantes passaram a adotar uma estratégia que permitia que seus interesses fossem levados ao seio da representação nacional: o exercício do direito de petição $^{17}$.

Registram-se, ao menos, cinco petições enviadas à Câmara dos Deputados: dos negociantes da Praça da Bahia de 1840, assinada por 54 comerciantes; da Associação Comercial de Pernambuco de 1840; da Associação Comercial da Praça da cidade da Bahia de 1841; da Comissão da Praça de Comércio do Rio de Janeiro de 1841; e, por fim, da

Associação Comercial de Pernambuco de $1842^{18}$. Nessas petições eram comuns pressões dos comerciantes exigindo melhorias das condições do comércio, como a criação de uma justiça comercial especializada e uma melhor regulamentação que visasse coibir condutas de má-fé e a ocorrência de falências fraudulentas. Conforme Eugene Ridings, a opção dos comerciantes em peticionar à Câmara dos Deputados e não ao Senado poderia ser justificada em razão de ser aquela mais ativa na criação de novas legislações ${ }^{19}$.

17 SABA, Roberto N. P. F. Op.Cit, p. 80.

18 Idem, pp. 80-83. 
19 RIDINGS, Eugene. Business Interest Groups in Nineteenth-Century Brazil. Cambridge University Press, 1994, pp. 58-59 apud SABA, Roberto N. P. F. Op. Cit., p. 80

Em 19 de julho de 1843, abriu-se nova sessão na Câmara dos Deputados. Em seu início, o deputado Pereira da Silva destacou que a Praça de Comércio do Rio de Janeiro havia dirigido à Câmara mais duas petições requerendo a aprovação do Projeto do Código $^{20}$. O deputado ainda fez questão de relatar todas as razões alegadas pelos negociantes signatários das petições. Pereira da Silva estava esperançoso que o Código Comercial seria a lei que solucionaria as necessidades do país, visto que proporcionaria proteção ao comércio através de seu regime de matrícula do comerciante num Tribunal do Comércio, e o tratamento das obrigações comerciais, razão pela qual pleiteou que o diploma fosse aprovado em globo pela Câmara dos Deputados ${ }^{21}$. Ato contínuo, o deputado José Cesário de Miranda Ribeiro afirmou que os trabalhos da comissão especial estavam concluídos, com uma grande quantidade de emendas ao seu texto.

Em 29 de agosto de 1843, reapareceu a discussão acerca do Código Comercial na Câmara dos Deputados. Ao cabo da aprovação de um parecer emitido por um desembargador, leu-se parecer informando a apresentação dos trabalhos da comissão nomeada para examinar o Código Comercial e disponibilizou-se o projeto impresso com emendas já incluídas 22 . No parecer também foi explicado o trabalho da comissão, que consultou códigos estrangeiros e os trabalhos de outras comissões, bem como recorreu a jurisconsultos para aperfeiçoar sua tarefa.

20 BRASI, Anais da Câmara dos deputados. Sessão de 19 de julho de 1843. P. 290. Disponivel em < http://imagem.camara.gov.br/diário.asp> Acesso e, 30.12.2015 
21 Idem,p. 291

22 BRASIL Anais da Câmara dos deputados. Sessão de 29 de agosto de 1843. p. 920. Disponivel em < http://imagem.camara.gov.br/diário.asp> Acesso e, 30.12.2015

Por fim, o parecer assim se manifestou:

\begin{abstract}
E como no entender das commissões reunidas o novo projecto, suposto não possa dizer-se obra perfeita, póde ser adoptado sem grave inconveniente na pratica, deixando-se á experiencia do tempo as emendas de que possa carecer; attendendose á urgente necessidade que existe de estabelecer regra certas que regulem a decisão das questões commerciaes, sujeitas até hoje ao livre arbitrio que a lei de 18 de Agosto de 1769 deixou ao julgadores de recorrerem às leis economicas, mercantis e maritimas; considerando tambem que petições dos commerciantes de diversas praças do imperio têm sido apresentadas a ambas as camaras, pedindo medidas legislativas que ponhão termo aos males que o commercio padece por falta de um codigo commercial; e observando finalmente que uma discussão por artigos fôra absolutamente impraticavel.

E" acomissão de parecer, de acordo com a comissão da camara dos SRs, senadores, que o novo projecto redigido pelas duas commissões se discuta e globo, approvando-se ou rejeitando-se, como parecer á sabedoria desta augusta camara. Paço da camara dos deputados, 28 de Agosto de 1843 - José Cesario de Miranda Ribeiro José Lopes da Silva Vianna.23
\end{abstract}

O parecer traz à luz a Lei da Boa Razão, já citada, que sujeitava os comerciantes à discricionariedade dos magistrados na aplicação da legislação. Tal situação reforça ainda mais a visão de que os negociantes da época enfrentavam forte insegurança em sua atividade em decorrência da defasada legislação sobre o tema, conforme exposto no capítulo anterior.

O parecer se posicionou no sentido da votação global do projeto, isto é, sem que fosse analisada emenda por emenda, o que, segundo seus termos, constituiria tarefa absolutamente impraticável. Após essa proposta, o Presidente da Câmara acentuou que a votação em globo constituiria uma alteração do regimento da casa, pois, conforme prescrições regimentais, nenhum projeto de decreto será “aprovado sem questão passado por três discussões, a $1^{\circ}$ e $3^{\circ}$ das quaes versará sobre o projecto em geral, e a $2^{\mathrm{a}}$ sobre cada um de seus artigos em particular 24. Alegou, ainda, que o art. 16025 do regimento proibia a alteração de seus dispositivos, salvo em virtude de uma indicação.

${ }^{23}$ Ibidem.

24 Ibidem.

25 "Art. 160. Nenhum artigo do regimento será mudado ou alterado senão em virtude de uma indicação que deverá passar pelos turnos das mais indicações". Revista Brasileira de História do Direito| e-ISSN: 2526-009X| Brasília | v. 2 | n. 1 | p. 01 - 27 | Jan/Jun. 2016. 
Desse modo, concluiu que a posição do parecer deveria ser convertida em mera indicação a ser remetida à mesa para manifestação, ficando impedido o presidente de consultar a Câmara nesta sessão.

O deputado Venâncio Henriques de Rezende se opôs à opinião apresentada, salientando que estava em desacordo com o regimento e os precedentes da Casa. O Presidente da Câmara registrou que sua convicção estava mantida e, assim, mudou os rumos da discussão. Contudo, na sessão do dia seguinte, isto é, em 30 de agosto de 1843, o debate instaurou-se novamente. O deputado Ferreira Pena requereu urgência para ler o parecer da mesa acerca da indicação da comissão especial encarregada do Código de Comércio, apoiado pelos demais parlamentares:

\begin{abstract}
A mesa examinou o parecer da comissão especial, lido na sessão de hontem, no qual indica que se discuta em globo o projecto de lei, contendo o código commercial que acompanhou o referido parecer; e considerando: $1^{\circ}$, que o debate de cada um dos 847 artigos, de que elle consta, teria de retardar por muito tempo a promulgação de uma lei, cuja falta se torna cada dia mais sensível; $2^{\circ}$, que o projecto em questão, depois de revisto por varias commissões, não só das camaras legislativas, como externas, acha- se já impresso e distribuido a cada um dos Srs. deputados, que, examinando-o, poderá ainda lembrar qualquer correcção que seja necessária; $3^{\circ}$, que em casos idênticos, e por diversas razões de utilidade publica, tem a camara resolvido dispensar algumas das disposições do regimento que regularão o andamento dos seus trabalhos, é de parecer que o projeto do código commercial tenha uma só discussão correspondente á terceira, nos termos do art. 135 do regimento, dispensado para este fim a disposição do art. 127. Paço da camara dos deputados, 30 de Agosto de 1843 Manoel Ignacio Cavalcanti de Lacerda, presidente. Herculano Ferreira Penna, $1^{\circ}$ secretario Angelo Muniz da Silva Ferraz, $2^{\circ}$ secretario (vencido). - Visconde de Baependy, $3^{\circ}$ secretario Luiz Carlos da Fonseca, $4^{\circ}$ secretario $^{26}$
\end{abstract}

Iniciou-se uma discussão acerca da urgência de votação do Código. O deputado Joaquim José Pacheco posicionou-se contrário, por entender que não havia nenhum inconveniente em adiar o debate sobre o parecer, enquanto que os deputados Pereira da Silva e Venâncio Henriques de Rezende votaram a favor. A urgência foi aprovada e o parecer da mesa entrou em discussão na Câmara.

26 BRASIL Anais da Câmara dos deputados. Sessão de 30 de agosto de 1843. p. 1843. Disponivel em < http://imagem.camara.gov.br/diário.asp> Acesso e, 31.12.2015 
O deputado Ângelo Muniz da Silva Ferraz restou vencido no parecer, porém registrou manter sua convicção de que a Câmara não poderia deixar de exercer o direito de examiná-lo com calma. Já para o deputado Carneiro da Cunha, as emendas viriam futuramente para corrigir os erros demonstrados pela prática. $O$ final da fala de Carneiro da Cunha demosntrou a fortepressão que os negociantes estavam fazendo como muitos negociantes da Parahyba e de Pernambuco me mostrarão a urgente necessidade desta lei, por isso é que eu prefiro ser approvada por uma resolução para evitar que a emenda seja peior" 27

O deputado Urbano Sabino Pessoa de Melo se manifestou dizendo que a votação do código não poderia ocorrer nesse ano, sustentando que a legislação brasileira permitia que o país recorresse às leis das nações mais civilizadas, razão pela qual não haveria tamanha pressa:

Existe o codigo de uma nação pelo qual o nosso fôro se tem regulado, e pode-se regular; nós temos a propria legislação que nos manda adotar a legislação de paizes civilisados; e quando ha questões, os juizes recorrem ao codigo de commercio da França; é o que eu tenho feito. Temos alguma legislação subsidiaria; eu estou convencido de que isto não é o sufficiente, mas emfim podemos continuar a regular por ellas durante os 6 ou 7 mezes que estudarmos o novo projecto que se nos offerece. ${ }^{28}$

O deputado Pereira da Silva voltou a discursar a favor da votação em bloco do projeto e, ato contínuo, criticou Urbano Melo, declarando que o parlamentar estava em descompasso em relação aos clamores da sociedade brasileira. Ressaltou que a aplicação das leis das nações mais civilizadas resultava em profunda incerteza jurídica, eis que cada magistrado julgava a lide conforme sua convicção. Alegou, por fim, que no Brasil não havia tipificação dos crimes familiares e votou a favor do parecer da comissão. 
O deputado Herculano Ferreira Penna se posicionou a favor do parecer, sob o argumento de que a votação em bloco não impediria emendas nos assuntos que de suma importância. Já o deputado José Alves da Cruz Rios afirmou não ter confiança no Código, votando contra o parecer. O deputado Urbano Sabino Pessoa de Melo retomou a palavra e destacou que não apenas nas questões comerciaia, mas como em "quase todas as questões se regulando pelo direito subsidiário, pelo direito romano e legislação das nações civilizadas 29 .

José Alves da Cruz Rios volta a discursar e salienta que o maior pleito dos comerciantes são as falências fraudulentas, porém, em sua visão, tal fato "provem mais da falta da execução das leis, do que absoluta dellas" 30 .Considerando que haviam leis a serem aplicadas, posicionou-se contra a discussão em bloco do projeto, mas não contra o Código Comercial. Por fim, a palavra passou ao deputado José Cesário de Miranda Ribeiro, que optou por tecer poucos comentários e votou a favor do parecer por entender que era a melhor solução para o caso. Assim, o parecer da comissão especial do Código Comercial foi aprovado:

Ao fim da discussão de 1843, o parecer da comissão especial do Código Comercial foi aprovado: os deputados do Império fariam somente uma discussão em globo. Contudo, o pedido de Urbano foi atendido: como somente no dia 18 de setembro a discussão teria início, o tempo necessário para os 12 discursos previstos no regulamento seria curto demais; Ferraz propôs o adiamento da discussão para a sessão seguinte e não teve dificuldades em ver esta medida aprovada.

Não se dando por vencido inteiramente, Pereira da Silva ainda propôs que os "negociantes nacionais e estrangeiros ilustrados" da Praça do Rio de Janeiro pudessem oficialmente remeter aos representantes da nação "as observações sobre tal projeto julgar conveniente, podendo assim a Câmara mais ilustrada discutir a matéria e adotar o projeto com aquelas modificações que entender necessárias." A proposta foi rejeitada. Os deputados já haviam cedido o suficiente a pressão dos comerciantes; permitir que comerciantes invadissem o debate seria incorrer num exagero; afinal, as petições já haviam cumprido este dever.31

\footnotetext{
29 Ibidem

30 Ibidem p. 953

${ }^{31}$ SABA, Roberto N. P. F. Op. Cit. P. 91.
} 
A Câmara dos Deputados foi dissolvida em 1844, assim os debates sobre o Código Comercial só voltaram a ocorrer em 1845. Na sessão de 2 de junho desse ano entrou em discussão o projeto. O primeiro parlamentar a tomar a palavra foi João José de Oliveira Junqueira, que reiterou a urgente necessidade de um Código Comercial que fosse apto a lidar com as demandas dos negociantes, especialmente a de coibir falências fraudulentas.

O deputado Joaquim Antão Fernandes Leão pediu a palavra, defendendo pontos técnicos do Código, tal como as disposições referentes à administração da justiça, e registrou que todos os presentes na casa teriam plena possibilidade de votá-lo, porque se deu tanta divulgação ao projeto que todos já estariam cientes de seus termos. Contudo, em seguida, o parlamentar baiano José Ferreira Souto passou a discursar e salientou que não poderia votá-lo, uma vez que não havia lido nem examinado o diploma. Destacou que confiava nos trabalhos feitos pelas comissões, mas acreditava que era necessária uma discussão cuidadosa dos parlamentares, razão pela qual pleiteou o adiamento da discussão.

O deputado Ângelo Muniz da Silva Ferraz tomou a palavra, registrou novamente a necessidade dos negociantes de um Código Comercial que pusesse fim à falta de legislação específica sobre a matéria, e teceu alguns comentários contrários sobre pontos técnicos do Código. Como exemplo, cita-se sua opinião acerca da reabilitação do comerciante falido:

Sr. Presidente, ha outro ponto sobre que chamarei a attenção da camara, e é aquelle em que os autores do codigo dão direito aos negociantes, convencidos de quebra, em que ha lugar a imposição de pena a rehabilitarem-se depois do cumprimento da pena e satisfação dos credores. O mal de que nós nos queixamos sempre é a facilidade das quebras; é preciso que haja um meio de apartar esses homens que se entregão a essa especie de negocio tão comesinho entre nós, e a possibilidade de uma rehabilitação muito anima a estes especuladores. Diz o art. 894. (Lê). Ora, daqui vê-se que, com a quitação dos credores e certidão do cumprimento da pena, póde dar-se a rehabilitação. Pela nossa legislação criminal, a pena só se inflige ao fallido de má fé, na banca-rota fraudulenta: como pois essa disposição; e isto quando no artigo seguinte é prohibida a rehabilitação ao bancarroteiro fraudulento? Eu quero que em todo o caso o homem convencido de quebra, que dê lugar á imposição de penas, não possa ser rehabilitado por maneira alguma, principalmente dando-se entre nós circumstância de que, por meio de empenhos, se obtem tudo ${ }^{32}$

32 BRASIL Anais da Câmara dos deputados. Sessão de 30 de agosto de $1843 . . \quad$ Disponivel em < http://imagem.camara.gov.br/diário.asp> Acesso em.11.01.2016 
Inobstante as críticas apresentadas, o deputado Ângelo Muniz da Silva Ferraz afirmou que não apresentaria emendas, pois caso fizesse iria prejudicar a sistematicidade do Código, preferindo que as alterações viessem com o tempo. Ato contínuo, voltou a discursar João José de Oliveira Junqueira, também tecendo alguns comentários acerca da má aplicação das leis falimentares já existentes e da reabilitação do falido. O deputado destacou outra característica problemática dos julgados brasileiros: o problema da morosidade da justiça. Ao final de sua fala, o parlamentar votou a favor do projeto. Encerrada a sessão, o debate teve que aguardar o dia seguinte, que seria o último obstáculo pelo qual passaria na Câmara dos Deputados.

Cabe registrar que o Instituto dos Advogados Brasileiros (IAB), formado por um grupo teoricamente neutro e especializado em assuntos legais, havia enviado uma petição à Câmara em 1845, defendendo a posição dos comerciantes do Rio de Janeiro ${ }^{33}$. Nota-se que a pressão pela aprovação do diploma vinha aumentando.

Na sessão de 3 de julho de 1845, tomou a palavra o deputado Joaquim Nunes Machado, passando a debater sobre a criação de tribunais comerciais. Em sua visão, tal situação poderia levar a uma espécie de monopólio dos grandes comerciantes que fossem eleitos seus deputados. Além disso, registrou que, inobstante fosse o projeto antigo, carecia ainda de uma discussão cautelosa para sua aprovação. Todavia, sua voz não convenceu seus pares e, após intenso debate, o projeto foi aprovado pela Câmara sem qualquer emenda. Prevaleceu a tese dos defensores do diploma, em resposta às pressões provenientes das praças comerciais do Império.

Em 1846 e 1847, o projeto passou por debates no Senado, que não serão aqui analisados por fugir ao escopo do trabalho. Ao final das discussões no Senado, o Código igualmente foi aprovado sem qualquer alteração ${ }^{34}$. Em razão de turbulências na Província de Pernambuco em 1848, a Câmara foi dissolvida em 1849, o que fez com que o projeto tivesse que aguardar mais um ano para que finalmente viesse a ser incorporado ao ordenamento jurídico brasileiro 35 .

33 SABA, Roberto N. P. F. Op. Cit. P. 91.

34 Idem, p. 93.

35 Ibidem 
Tão somente no ano de 1850 foi formada uma comissão parlamentar composta por Eusébio de Queiroz (presidente), José Clemente Pereira, Caetano Alberto Soares, José Thomas Nabuco de Araújo, Francisco Ignácio de Carvalho Moreira e Irineu Evangelista de Souza e, em 25 de junho daquele ano, o Código Comercial finalmente foi promulgado.

\section{O TRATAMENTO DA JUSTIÇA COMERCIAL E DA FALÊNCIA NO CÓDIGO COMERCIAL}

Neste tópico será apresentado o tratamento dado pelo Código Comercial a dois temas recorrentes nos pronunciamentos dos deputados ao longo da discussão sobre o diploma em comento: a criação de uma justiça comercial especializada e a questão da falência, com especial objetivo de coibir as quebras fraudulentas.

\subsection{A especialização da justiça comercial no Código Comercial}

Com o advento do Código Comercial, criaram-se os Tribunais do Comércio 36 em seu Título Único (Da Administração da Justiça nos Negócios e Causas Comerciais), art. $1^{\mathrm{o}}$ :

Art. $1^{\circ}$. Haverá Tribunaes do Commercio na Capital do Imperio, nas Capitaes das Provincias da Bahia e de Pernambuco, e nas Provincias onde para o futuro se crearem, tendo cada hum por districto o da respectiva Provincia.

Nas Provincias onda não houver Tribunal do Commercio, as suas attribuições serão exercidas pelas Relações; e, na falta destas, na parte administrativa, pelas Autoridades Administrativas, e na parte judiciária, pelas Autoridades Judiciárias que o Governo designar (art. 27). 
Conforme art. $2^{\circ}$ do Título Único, o Tribunal do Comércio na capital do Império seria composto por um presidente letrado, seis deputados comerciantes, servindo um na condição de secretário, e três na de suplentes, também comerciantes. Teria ainda um fiscal adjunto, que necessariamente era um desembargador. Já os Tribunais das Províncias seriam compostos por um presidente letrado, quatro deputados comerciantes, servindo um na condição de secretário e dois, na de suplentes, também comerciantes. Igualmente, haveria um fiscal adjunto, que seria um desembargador.

Considerando-se a realidade da sociedade brasileira da época o art. 14 fez uma ressalva, prescrevendo um requisito censitário para que determinado indivíduo fosse qualificado para exercer o cargo de deputado do Tribunal serão admitidos a votar e ser votado os negociantes que tiverem ou se presumir terem hum capital de quarenta contos" Trata-se de um critério dúbio, pois, ao mesmo passo que visa assegurar que apenas comerciantes experientes pudessem exercer tal $\operatorname{cargo}{ }^{37}$, igualmente evitava que pessoas com menos posse pudessem chegar a tal posição 38 .

A competência da jurisdição comercial ${ }^{39}$ poderia ser determinada em razão dos atos de comércio. O Código não definiu o que seria mercancia 40 no artigo $4^{\circ}$, matéria esta que restou tratada nos arts. 19 e 20 do Regulamento n. 737, de 25 de novembro do mesmo ano.

Para Rubens Requião, a omissão do legislador codificador foi proposital:

37 Para atingir esse objetivo, outros requisitos eram previstos. Veja-se, por exemplo, o quie dispõe o art. 15: "Nenhum commerciante pode ser Deputado ou Supplente, antes de trinta anos completos de idade, e sem que tenha ao menos cinco anos de profissão habitual de comercio. A nomeação do Presidente não poderá recair em pessoa que tenha menos da referida idade". 38 Cita-se, por exemplo, o art. 94, I, da Constituição de 1824, que estipulou o voto censitário: "Podem ser Eleitores, e votar na eleição dos Deputados, Senadores, e Membros dos Conselhos de Províncias todos, os que podem votar na Assembléa Paroquial. Exceptuam-se: I. Os que não tiverem a renda liquida anual duzentos mil réis por bens de raiz, industria comercio, ou emprego". 39 Sobre a jurisdição voluntária, cabe registrar que sua previsão decorria do artigo art. $8^{\circ}$ do Título Único: "Aos Tribunaes do Commercio competirá, além das atribuições expressamente declaradas no Codigo Comercial, aquela jurisdicção voluntária inerente a natureza da sua instituição, que for marcada do Regulamentos do Poder Executivo (art.27)".

40 Para lição histórica de José Xavier Carvalho de Mendonça, "Mercancia é synony,p de actpr de commercio, e o exercito destes constitue uma indústria que tem sua espera economica e juridica própria, como succede com a industria agrícola e com a manufactureira ou fabril". (CARVALHO DE MENDONÇA, José Xavier. Das fallencias e dos meios preventivos de sua declaração: Decr. N. 917, de 24 de outubro de 1890, estudo theorico-pratico, v I. São Paulo: Typogbaphia Brasil de Carlos Gerke \& Cia, 1899, p.49, Disponível em:<https://www.oab.org.br/editora/revista/1205508881174218181901.pdf >. Acesso em 04.02.2016) 
Tal foi a impressão que as controvérsias do sistema enumerativo dos atos de comércio adotados pelo Código francês, e dos que lhe seguiram, causaram em nosso país, cuja cultura jurídica se abeberava na doutrina francesa, que levou os legisladores brasileiros do Código Comercial de 1850 a abandonar a técnica enumerativa. Eis por que o nosso Código Comercial propositadamente silencia sobre os atos de comércio, cuja expressão chega mesmo a evitar seu texto. [...] Adota, assim, o Código, o sistema acentuadamente subjetivo, pois, como comenta Jean Escarra, não existe, no direito positivo, sistema objetivo ou subjetivo puros. Assenta o Código, aparentemente, o seu sistema na definição de comerciante para efeito de gozar da proteção que este Código liberaliza em favor do comércio, sem que se tenha matriculado em algum dos Tribunais do Comércio do Império e faça da mercancia profissão habitual" ${ }^{41}$

Contudo, o Regulamento n. 737 veio a complementar o Código, rendendo-se à técnica enumerativa dos atos de comércio. Continua Rubens Requião:

Foi necessário, todavia, ao Regulamento $\mathrm{n}^{\mathbf{0}} 737$, complementando o Código, esclarecer, para efeito de se determinar a competência dos Tribunais de Comércio relativamente aos comerciantes, o que se devera reputar por mercancia. Impossível, portanto, fugir à enumeração dos atos de comércio.42

O rol previsto no art. 19 do Regulamento n. 737 era exemplificativo ${ }^{43}$. Com isso, o sistema brasileiro foi considerado misto: subjetivo, uma vez que se assentava na figura do comerciante, e objetivo, por enumerar legalmente os atos de comércio, a fim de esclarecer o que seria considerado mercancia, elemento central na conceituação do comerciante. ${ }^{44}$

A Junta de Comércio era detentora de jurisdição exclusiva para conhecer de matérias falimentares, em conjunto com a Secretaria de Estado. Com a inauguração da justiça comercial, tal matéria evidentemente estaria inserida em seu rol de competência.

Veja-se lição de José Xavier Carvalho de Mendonça:

41 REQUIÃO, Rubens. Curso de Direito Comercial. vol 1, 26. ed. São Paulo: Saraiva, 2005, p. 36.

42 Ibidem.

$43 \mathrm{O}$ art. 19 dispunha que era considerada mercancia: (1) "A compra e venda ou troca de effeitos moveis ou semoventes para os vender por grosso ou a retalho, na mesma especie ou manufacturados, ou para alugar o seu uso" (2) "As operações de cambio, banco e corretagem"; (3) "As empresas de fabricas; (4) "Os seguros, fretamentos, riso, e quaesquer contratos relativos ao commercio marítimo"; e, por fim (5) "A armação e expedição de navios".

44 Com a entrada em vigor de Código Civil de 2002, passou-se a adotar a teoria da empresa. A atual codificação brasileira na conceituou a atividade empresária em si, porém em seu art. 966, considerou o empresário como sendo aquele "quem exerce profissionalmente atividade econômica organizada para a produção ou a circulação de bens ou de serviços". Portanto, extrai-se o conceito de empresa a partir do empresário, que pode ser tanto pessoa física ou jurídica. $O$ vocábulo 'empresa' passa a ser objeto de direito e o 'empresário', a pessoa fisica ou jurídica, sujeito de direito, que exerce a empresa. 
Nos Estados a declaração da fallencia pertence á jurisdicção commercial (competência ratione matéria), quer seja exercida especialmente, quer cumulativamente com a civel, na conformidade das respectivas leis orgânicas judiciárias. Instituição essencialmente mercantil, já fallencia vae agrupar-se entre as causas sujeitas áquella jurisdicção.

A jurisdicção, em relação ao seu objecto, é contenciosa ou graciosa (esta também chamada voluntária ou administrativa), segundo garante ou restabelece direitos ameaçados ou lesados, ou apenas concede garantias contra possíveis lesões futuras.

As causas de fallencia pertencem á jurisdicção contenciosa. A fallencia é meio extraordinário de execução (n. 25), e no seu curso podem surgir embargos á declaração da fallencia, embargos de terceiros, embargos á concordata, reclamação sobre a classificação de créditos, sem esquecer as acções de nulidade e quaesquer outras intentadas contra a massa, as quaes são sempre processadas summariamente perante o juiz da fallencia. 45

O juiz comercial competente para declarar a falência era aquele em cuja jurisdição o devedor tivesse seu principal estabelecimento, considerado o local de seu domicílio ou sede, isto é, "onde centralisa a sua atividade e influencia economica, onde todas as suas operações recebem o impulso director, onde saca, endossa e acceita letras; onde, enfim, se acham reunidos normal e permanente todos os elementos constitutivos do seu credito" 46

\subsection{O tratamento da falência no Código Comercial}

Impõe-se agora tecer comentários sobre o tratamento conferido à falência pelo Código. Inicialmente, veja-se a conceituação do instituto, com lastro na obra de José da Silva Lisboa:

Fallimento to he expressão contraria ao Credito, e abonação mercantil; e suppõe falta de fundos, mudança de estado, isto he, alteração na fortuna, e reputação do Commerciante, constituindo-se no descredito, e impossibilitado de satisfazer as suas obrigações. 47

45 MENDONÇA, José Xavier Carvalho de. Op. Cit., p. 91.

46 Idem, p. 92.

47 Cayru, José da Silva Lisboa, Visconde de. Op. Cit, p. 867.

Revista Brasileira de História do Direito | e-ISSN: 2526-009x | Brasília | v. 2 | n. 1 | p. 01 - 27| Jan/Jun. 2016. 
Sobre a terminologia, a palavra falência se origina do latim fallere, que significa faltar48. Nesse diapasão, Antonio Bento de Faria, em histórica obra sobre o Código Comercial, apontou que o termo exprimia "a falta calculada ás obrigações, o engano nos contractos, a illusão nas expectativas, a falsidade nas promessas"49

Para José Xavier Carvalho de Mendonça, similarmente, falência significava enganar, descumprir o prometido, se omitir na observância de um dever, isto é, falhar no cumprimento exato de uma obrigação50. Outros termos utilizados eram bancarrota, derivado da expressão banco rotto (banco quebrado)51, e quebra. Elucida o autor:

\begin{abstract}
A technica jurídica acceitou em seu vocabulário a palavra fallencia para designar o estado do commerciante que deixou de fazer frente a seus compromissos, que cessa os seus pagamentos, ou melhor que se, acha impossibilitado de satisfazer as suas obrigações.

Quebra parece ser a verdadeira palavra portugueza para enunciar esse estado; encontramol-a empregada desde as Ordenações e muito antes da entrada do termo fallencia nos monumentos legislativos. Hoje, porém, são synonymas, e aquella vae sendo abandonada e substituida por esta.
\end{abstract}

Bancarrota não expressão que fosse adoptada em nosso direito. No Francez, Belga, Italiano e outros é reservada á fallencia em que se prova culpa ou fraude do devedor.52

Em sentido semelhante, posiciona-se Antonio Bento de Faria:

$\mathrm{Na}$ antiga legislação portugueza (Ord. L. 5 Tit. 66), -quebra era propriamente bancarrota, fallencia com fraude ou culpa (Magalhães. Codigo Portuguez das fallencias annotado, pag. 24).

Hoje, porém, quebra e fallencia são synonimos, sendo que o ultimo destes termos é, em geral, consagrado para designar a insolvencia do commerciante de boa ou de má fé.

Não obstante, porém, ainda alguns Códigos adoptão a expressão bancarrota para designar a fallencia acompanhada de culpa ou fraude do devedor. Cods. Commerciaes: Francez arts. 284 e seguintes; Italiano art. 856 e seguintes; Belga art. 573; Roumaico art. 869 e seguintes.53

\footnotetext{
48 FARIA, Antonio Bento de. Codigo Commercial Brasileiro, anotado de acordo com a doutrina, a legislação e a jurisprudência nacional e estrangeira, e os princípios e regras do direito civil, seguido do Regulamento n. 737 de 1850 , igualmente anotado, de um Indice alphabetico e deum appendice contendo todas as leis commerciais em vigor e que lhe são referentes. Rio de Janeiro: Jacintho Ribeiro dos Santos editor, 1903, p.505.

49 Ibidem.

50 MENDONÇA, José Xavier Carvalho de. Op. Cit. 39.

51 CORREA-LIMA, Osmar Brina; CORREA-LIMA, Sérgio Mourão (Orgs.). Disposições Preliminares e Institutos comuns à Recuperação Judicial e à Falência - Artigos1 até 46. V. I. Rio de Janeiro: Forense, 2009, p.14.

52 MENDONÇA, José Xavier Carvalho de. Op. Cit. 40.
} 
Inobstante não seja bancarrota uma expressão de origem portuguesa, os deputados e comerciantes recorreram a ela muitas vezes em seus debates e escritos. Desse modo, para fins de facilitação da compreensão do presente artigo, as três expressões podem ser tratadas como sinônimos.

De outro giro, o art. 798 do Código Comercial estipulou que a "quebra ou falência pode ser casual, com a culpa ou fraudulenta". A falência seria considerada casual quando a insolvência procedia "de accidentes de casos fortuitos ou força maior" (art.799), ao passo que seria culposa quando a insolvência ocorresse dentro das hipoteses de um dos incisos do art. 800: (1) "Excesso de despesas no tratamento pessoal do falido, em relação ao seu cabedal e número de pessoas de sua família"; (2) "Perdas avultadas a jogos, ou especulação de aposta ou agiotagem"; (3) "Venda por menos do preço corrente de efeitos que falido comprara nos seis meses anteriores a quebra, e se ache ainda devendo"; e (4) "Acontecendo que os fallido, entre a data do seu ultimo balanço (art. 10 n. 4) e a da fallencia (art. 806), se achasse devendo por obrigações diretas o dobro do ser cabedal apurado nesse balanço".

Conforme lição histórica de Salustiano Orlando d'Araujo Costa, o art. 800 estava em consonância com a legislação estrangeira da época, com especial destaque ao art. 1147, n. 1, do Código Comercial português e o art. 586 do Código Comercial francês54.

A falência também seria qualificada com culpa caso o falido incorresse em uma das situações descritas no art. 801: (1) "Quando o fallido não tiver a sua escripturação e correspondencia mercantil nos termos regulados por este Codigo (arts. 13 e 14)"; (2) "Não se apresentando no temo e na forma devida (art. 805)"; (3) "Ausentando-se ou ocultandose".

53 FARIA, Antonio Bento de. Op. Cit.; p.546.

54 COSTA, Bacharel Salustiano, Orlando d'Araujo. Codigo Commercial do Império do Brasil anotado com toda a legislação do pais que lhe é referente; com todos os arrestos e decisões dos tribunaes; confrontando em seus artigos com a legislação comercial de diferentes países estrangeiros, especialmente com as disposições dos códigos frances, portugues e holandes; acompanhado dos três principais regulamentos sob ns. 737, 738 e 1597 também anotados com um interessante e vasto apendice e diferentes disposições cujo conhecimento se torna indispensável aos negociantes e ao foro comercial. Acompanhado do novo regulamento do papel selado também anotado. Edição única completa. Rio de Janeiro: Eduardo \& Henrique Laemmert editores, 1864, p. 218. 
O Código estipulou que falência era fraudulenta se estivesse prevista em uma das hipóteses do art. 802: (1) Despesas ou perdas ficticias, ou falta de justificação do emprego de todas as receitas do fallido"; (2) "Occultação no balanço de qualquer somma de dinheiro, ou de quaesquer bens ou titulos (art. 805)"; (3) Desvio ou applicação de fundos ou valores de que o fallido tivesse sido depositário ou mandatário"; (4) "Vendas, negociações e doações feitas, ou dividas contrahidas com simulação ou fingimento"; (5) "Compra de bens em nome de terceira pessoa"; e (6) "Não tendo o fallido os livros que deve ter (art. 11), ou se os apresentar truncados ou falsificados. Esta disposição estava em consonância com o art. 1.149 do Código Comercial português e o art. 593 do Código Comercial francês55.

No caso da falência casual não havia qualquer previsão de punição ao falido, mas se ela fosse considerada culposa, lhe infligiriam as penas56 do art. 828. Por fim, em relação à falência fraudulenta, seriam aplicadas as disposições do Código Criminal e seus fatos teriam que ser apurados em processo penal distinto do comercial:

\footnotetext{
A fallencia ou póde ser unicamente devida ao acaso ou revezes de fortuna do commerciante honesto, ou determinada pelos abusos, erros e desregrado procedimento do devedor de má-fé.

No primeiro caso seria injusto punil-o; no segundo, porém, a repressão impõe-se como medida de ordem publica, na defesa dos interesses sociaes. Assim, é que a fallencia se divide em: casual, culposa e fraudulenta.

Como, porém, as decisões proferidas no civil, relativamente aos interesses privados não influem necessariamente nos julgamentos dos Tribunaes de repressão, cumpria apurar em processo distincto e separado em qual das gradações estabelecidas podiam- se ajusar os factos practicados pelo fallido. $\mathrm{O}$ processo criminal, portanto, não indica necessariamente a existência de um crime, apenas visa apural-o.

Para classificação da fallencia, sómente se deve ter em vista as provas colhidas no processo criminal, que em cousa alguma fica dependente dos critérios fornecidos pelo processo commercial. 57
}

55 Ibidem.

56 Art. 828 do Código Comercial: "Todos os actos do fallido alienativos de bens de raiz, moveis ou semoventes, e todos os mais actos e obrigações, ainda mesmo que sejão de operações commerciais, poder ser anulados, qualquer que seja a época em que fossem contrahidos, em quanto não prescreverem, provando-se que neles interveio fraude em damno de credores". 57 FARIAS, Antonio Bento de. Op., p. 649. 
Questão que se discutia à época era a possibilidade do juízo criminal conhecer da nulidade de sentença declaratória de falência, anulando sua abertura. José Xavier Carvalho de Mendonça sintetiza a posição da jurisprudência da instância excepcional, adotada alguns anos após a entrada em vigor da codificação comercial:

O extincto Supremo Tribunal de Justiça, por sentença de 20 de Setembro de 1865, na revista crime n. 1843, julgou que os juizes e tribunaes criminaes não tinham jurisdicção sobre os actos decisórios em processo de fallencia e não podiam annullar abertura desta, pois usurpariam a jurisdicção commercial. O Ac. Revisor da Relação do Rio, de 29 de Maio de 1866, confirmou essa doutrina.

Posteriormente, na revista crime n. 2604, o mesmo Supremo Tribunal, em sentença de 8 de Outubro de 1887, ordenou a revisão do processo criminal promovido contra um fallido sob o fundamento da nulidade da sentença declaratória da fallencia. A Relação da Bahia, no Ac. Revisor de 3 de Fevereiro de 1888, conformou-se com esta doutrina.58

Por fim, analisa-se a questão da reabilitação do falido. O artigo 893 estipulou que "o fallido que tiver obtido quitação plena de seus credores pode pedir a sua rehabilitação perante o Tribunal de Commercio que declarou a quebra". Para Salustiano Orlando d'Araujo Costa, a reabilitação, da forma que foi prevista, somente poderia ser decretada por um Tribunal de Comercio, não sendo uma prerrogativa garantida do comerciante matriculado59. Messe sentido, previu o art. 894, mencionado expressamente pelo deputado Ângelo Muniz da Silva Ferraz nos debates do projeto, que, sendo a falência considerada culposa, estaria "no arbitrio do Tribunal, procendo as averiguações que julgar convenientes, conceder ou negar a rehabilitação".

Ademais, respondendo às preocupações dos deputados, o art. 895 vedou a reabilitação nos casos de falência fraudulenta, disposição esta que estava em consonância com os Códigos Comerciais de Portugal (art. 1.264), Espanha (art. 1.170), França (art. 612) e Holanda (art. 893)60. A sentença que concedesse ou denagasse a reabilitação era considerada irrecorrível, porém a lei facultava a reforma da sentença denegatória, caso fossem apresentados, novos documentos pelo falido que abonassem "a sua regularidade de conduta" após seis meses (art.895). Por fim, estipulou o art. 897 que, uma vez concedida a reabilitação, cessariam "todas as interdicções legaes produzidas por efeitos da declaração da quebra"

58 CARVALHO DE MENDONÇA, José Xavier. Op. Cit., p. 234.

59 COSTA, Bacharel Salustiano Orlando d'Araujo Costa. Op. Cit., p. 250.

60 Ibidem. 
A preocupação em analisar a possibilidade de reabilitação à luz da falência com ou sem fraude existia antes da elaboração da codificação. Já se via na lição de José da Silva Lisboa que o instituto era previsto apenas para situações de falimento sem fraude, hipótese que, semelhante ao que dispôe o art. 897 do Código, não poderia deixar qualquer interdição legal ao falido.

\begin{abstract}
Em qualquer dos casos de Ponto, ou Quebra, alcançando o Devedor compromisso, ou concordata de seus Credores com permissão de continuar seu commercio, se considera rehabilitado para negociar, e exercer a profissão de Homem de Negocio, empenhando- se nas especulações que julga a propósito de seus interesses, e o bem da massa geral.

A concessão de tal graça dos Credores se diz ressureição civil; pois reintegra ao Devedor nos direitos de Commerciante, e isto na parte mais vital de sua profissão, para poder comparecer em Praça e fazer as transacções que entender sem diminuição de seu crédito, em que principalmente consiste a vida de tal exercicio, ou emprego da Sociedade nos Paizes civilisados.61
\end{abstract}

\title{
5. CONCLUSÃO
}

Ao longo do trabalho, buscou-se analisar os debates travados na Câmara dos Deputados nos anos precedentes à aprovação do Código Comercial. Constatou-se que a pressão exercida pelos comerciantes surtiu considerável efeito no legislativo, tendo em vista que alguns deputados atuaram ativamente em defesa da elaboração urgente do Código, que atendesse ao interesse dos setores dominantes, culminando na aprovação em bloco do diploma. No entanto, percebeu-se que o efeito prático da pressão não foi eficaz, haja vista que, em decorrência da dissolução da Câmara em 1848, o Código só veio a ser promulgado em 25 de junho de 1850.

Ademais, como questão prévia, o ordenamento jurídico do Império anterior ao Código era regido por uma confusa teia normativa colonial, estando defasando em vários aspectos. A solução encontrada era a aplicação de leis das chamadas "nações mais civilizadas, que, certamente, não conferia qualquer segurança jurídica para aqueles que atuavam no comércio.

61 CAYRU, José da Silva Lisboa, Visconde de. Op. Cit., p. 868. 
Exemplificativamente, tratou como restaram refletidas duas das demandas dos comerciantes no Código Comercial. A primeira foi a questão de uma justiça comercial especializada regulada pelo Título Único do diploma estudado. O legislador optou pela criação de um perfil elitista de julgadores, impedindo a ascensão de comerciantes de menor porte econômico. A segunda foi o aspecto punitivo da falência, que teve um tratamento mais uniforme em comparação à legislação precedente e buscou evitar, ao máximo, as fraudes dos comerciantes que atuavam de má-fé.

\section{REFERÊNCIAS}

BRASIL, Anais da Câmara dos Deputados. Sessões de: 01 de Julho de 1843; 19 de Julho de 1843; 29 de Agosto de 1843; 30 de Agosto de 1843; 02 de Julho de 1845; 03 de Julho de 1845. Disponível em: 〈http://imagem.camara.gov.br/diarios.asp〉. Acesso em 29.12.2015.

MENDONÇA, José Xavier Carvalho de. Das fallencias e dos meios preventivos de sua declaração: Decr. N. 917, de 24 de outubro de 1890, estudo theorico-pratico. v. I. São Paulo: Typogbaphia Brasil de Carlos GeRKE \& Cia, 1899. Disponível em: <http://www.oab.org.br/editora/revista/users/revista/1205508881174218181901.pdf>. Acesso em 04.02.2016.

CAYRU, José da Silva Lisboa, Visconde de. Principios de direito mercantil e leis da Marinha, divididos em sete tratados elementares, contendo a respectiva legislação patria, e indicando as fontes originaes dos regulamentos marítimos das principaes praças da Europa. Tomo II, 6. ed. Rio de Janeiro: Typographia Academica, 1874.

CORRÊA-LIMA, Osmar Brina; CORRÊA-LIMA, Sérgio Mourão (Orgs.). Disposições Preliminares e Institutos comuns à Recuperação Judicial e à Falência Artigos 1 até 46. v. I. Rio de Janeiro: Forense, 2009.

COSTA, Bacharel Salustiano Orlando d'Araujo Costa. Codigo Commercial do Império do Brasil anotado com toda a legislação do país que lhe é referente; com todos os arrestos e decisões dos tibunaes; confrontado em seus artigos com a legislação commercial de diferentes países estrangeiros, especialmente com as disposições dos códigos francês, português e holandes; acompanhado dos três principais regulamentos sob ns. 737, 738 e 1597 também anotado com um interessante e vasto apendice e diferente disposições cujo conhecimento se torna indispensável aos negociantes e ao foro commercial. Acompanhado do novo regulamento do papel selado também anotado. Edição única completa. Rio de Janeiro: Eduardo \& Henrique Laemmert editores, 1864. 
FARIA, Antonio Bento de. Codigo Commercial Brazileiro, annotado de accordo com a doutrina, a legislação e a jurisprudência nacional e estrangeira, e os princípios e regras do direito civil, seguido do Regulamento n. 737 de 1850, igualmente annotado, de um Indice alphabético e de um appendice contendo todas as leis commerciais em vigor e que lhe são referentes. Rio de Janeiro: Jacintho Ribeiro dos Santos editor, 1903.

FONSECA, Ricardo Marcelo. A cultura jurídica brasileira e a questão da codificação civil no século XIX. Revista da Faculdade de Direito UFPR. V. 44, n. 0 (2006). Disponível em: < http://ojs.c3sl.ufpr.br/ojs2/index.php/direito/article/view/9415/6507>. Acesso em 28.12.2015;

Introdução Teórica à História do Direito. $3^{\text {a }}$ reimpressão. Curitiba: Juruá, 2012. REQUIÃO, Rubens. Curso de Direito Comercial. vol. 1, 26. ed. São Paulo: Saraiva, 2005.

RIDINGS, Eugene. Business Interest Groups in Nineteenth-Century Brazil. Cambridge University Press, 1994.

SABA, Roberto N. P. F. As praças comerciais do Império e a aprovação do Código Comercial Brasileiro na Câmara dos Deputados. Revista Angelus Novus, n ${ }^{\circ}$ 1, agosto de 2010. Disponível em: <http://www.revistas.usp.br/ran/article/viewFile/88831/91705>. Acesso em 28.12.2015. 